Int. J. Plant Sci. 168(2):215-228. 2007.

(c) 2007 by The University of Chicago. All rights reserved.

1058-5893/2007/16802-0008\$15.00

\title{
REPRODUCTIVE ASSURANCE AND THE EVOLUTION OF POLLINATION SPECIALIZATION
}

\author{
Charles B. Fenster ${ }^{1, *} \dagger$ and Silvana Martén-Rodríguez† \\ *Plant Reproductive Biology, Xishuangbanna Tropical Botanical Garden, Chinese Academy of Sciences, Menglun Town, \\ Mengla County, Yunnan 666303, China; and tDepartment of Biology, University of Maryland, \\ College Park, Maryland 20742, U.S.A.
}

\begin{abstract}
Flowers with highly specialized pollination systems sometimes have the ability to self-pollinate, contradicting our notion that pollination specialization reflects selective pressures to ensure high maternal outcrossing rates. We survey the literature ( 80 species representing 38 families) for the simultaneous study of pollination and breeding systems. We demonstrate that pollination specialization is often associated with a variety of floral traits that facilitate delayed autonomous selfing at the end of the flower's life span. While the potential autonomous selfing rate can be high, the actual autonomous selfing rate is often much lower, indicating that species in our survey are facultative selfers. Autonomous selfing was more commonly associated with protandry than with protogyny and was found in both herkogamous and nonherkogamous species. We conclude that pollination specialization can evolve independently of the ability to autonomously self-pollinate and that the presence of floral traits that promote pollination specialization and autonomous selfing in the same flower is not paradoxical. Pollination specialization can be reconciled with autonomous self-pollination when selective forces other than high maternal outcrossing rates are considered.
\end{abstract}

Keywords: breeding system, mating system, pollen limitation, pollination syndromes, pollinator specialization, selfing.

The whole case is perplexing in an unparalleled degree for we have in the same flower elaborate contrivances for directly opposed objects. (C. Darwin 1877, p. 57)

\section{Introduction}

Thus was Darwin puzzled at the observation that the highly elaborate flower of the European orchid Ophrys apifera (fig. 1A) is capable of complete seed set in the absence of pollinators. The flowers produce compounds that attract the bees Tetralonia cressa and Eucera pulveraceae (Dafni 1987; Correvon and Pouyanne [1916], cited in Pouvreau et al. 1988; Kullenberg [1976], cited in van der Cingel 1995; Schiestl et al. 1999), and they elicit pseudocopulatory behavior in Eucera longicornis males (Paulus and Gack 1990; M. Ayasse, personal communication). While O. apifera represents a very specialized pollination system, pollinia removal observations suggest an upper-bound estimate of outcrossing at $8 \%$ (Darwin 1877), and the predominant mode of pollination corresponds to the caudicles of the pollinia bending into the stigma, effecting autonomous self-pollination.

Recent findings from tropical China (Zhang et al. 2005) mirror Darwin's observations. Highly elaborate flowers of Tacca chantrieri (Taccaceae), baroque in their exaggeration (fig. $1 B$ ), are highly selfing. This species manifests a suite of floral characters consistent with sapromyiophily (fly pollination), including "dark floral colors, the presence of filiform appendages or bracts, floral traps, absence of nectar and a

11E-mail cfenster@umd.edu.

Manuscript received February 2006; revised manuscript received July 2006. decaying odor" (Zhang et al. 2005, p. 522). Tacca chantrieri is not only capable of setting seed without pollinators but actually does so in natural populations. Outcrossing estimates using genetic markers indicate that $86 \%$ of seeds in one population were derived from selfing.

What is puzzling about these flowers is that they appear to invest sizably in floral structures yet are highly selfing. This is unexpected. Zhang et al. (2005) emphasize that a "rarely tested but fundamental assumption" is that the evolution of pollinator specialization, reflecting pollination syndromes, reflects natural selection promoting cross-pollination. Thus Darwin's puzzlement over the opposing contrivances within O. apifera: features to attract a specific group of pollinators to promote outcrossing and other features that facilitate selfpollination. For both $O$. apifera and $T$. chantrieri, the evolution of floral traits associated with highly specialized pollination systems has apparently failed miserably in terms of ensuring outcrossing.

However, we know from Darwin's consideration of Ophrys that self-fertilization can be adaptive when pollinators are absent, i.e., that selfing can act as reproductive assurance in the face of a variable pollinator environment (Darwin 1877, p. 58). This conclusion has been extended by subsequent theory (Lloyd 1979; Schoen and Brown 1991; Lloyd and Schoen 1992; Holsinger 1996; Morgan and Wilson 2005; reviewed in Goodwillie et al. 2005). One might say that Darwin answered the question of his own conundrum. If specialized pollination 


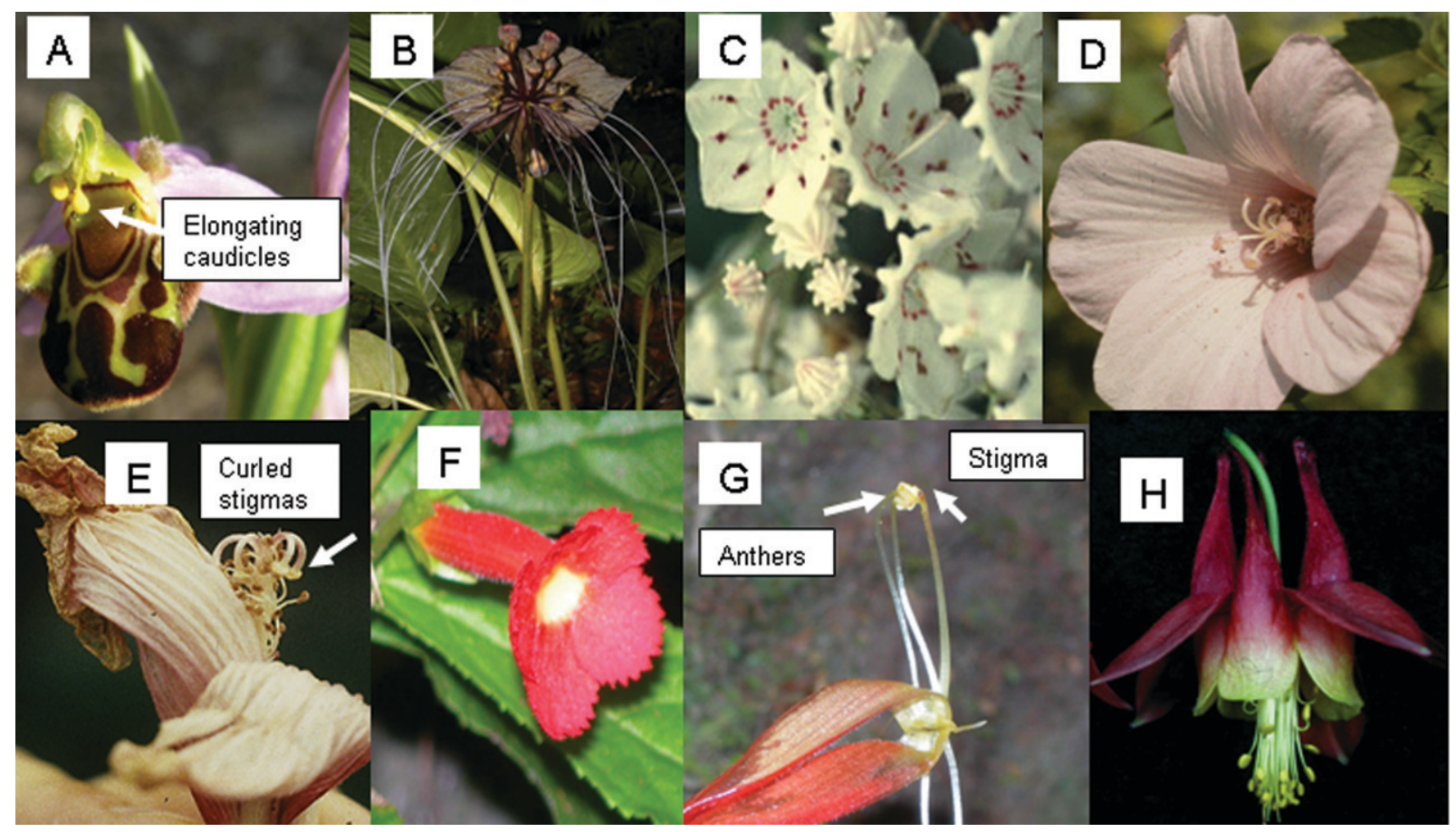

Fig. 1 A, Ophrys apifera is a member of a genus that mimics female Hymenoptera, inducing pseudocopulatory behavior by males leading to pollination. Ophrys apifera is pollinated by males of the bee genus Eucera, but, unlike other members of the genus, it is capable of delayed selfpollination through the elongation of the caudicles throughout the life span of the flower and is highly selfing (photo courtesy of http:// herbarivirtual.uib.es [Universitat de les Illes Balears]). B, Tacca chantrieri manifests many floral traits corresponding to fly pollination, yet it has a high selfing rate, likely corresponding to delayed selfing, when the flower inverts and the pollen spills onto the stigma (photo courtesy of Q.-J. Li). C, Kalmia latifolia is pollinated by large bees that trip the anther filaments (held in tension by depressions in the corolla), depositing pollen on the lateral surfaces of the bee. When the flower is not pollinated, the anthers may be dragged over the stigma as the corolla is shed (photo courtesy of E. Nagy). D, E, Hibiscus laevis, pollinated by large bees, is representative of many members of the Malvaceae in that toward the end of the flower's life span $(E)$, the stigmas curl down and back toward the anthers, resulting in delayed selfing (both photos courtesy of R. Klips). F, G, Gesneria reticulata is a hummingbird-pollinated species with slightly protogynous flowers. The stamens are taller than the pistil, but delayed selfing occurs $(G)$ when the style bends over, causing pollen in the anthers to be deposited onto the stigma (photos by S. Martén-Rodriguez). $H$, Aquilegia canadensis is hummingbird pollinated and slightly protogynous. When populations in southern Ontario are not visited by hummingbirds, the close proximity of anthers and stigma facilitate delayed selfing (photo courtesy of C. Eckert).

systems typically experience reduced seed set because of the inherent liability of investing all of one's floral resources into attracting a small subset of the potential pollinator community, then there should be selection for reproductive-assurance mechanisms. However, this would be to take Darwin (1877) out of context and ignore the main thrust of his argument, in which he viewed the selective pressures for pollination specialization and reproductive assurance as being in opposition. To reemphasize, the evolution of floral traits resulting in pollination specialization should reflect selection for increased outcrossing rates. Thus, the evolution of reproductive-assurance mechanisms in tandem with or subsequent to the evolution of pollination specialization would indicate that pollination specialization has not evolved in response to selection for increased outcrossing rates, relative to an ancestral condition of more generalized pollination.

Different mechanisms may underlie the production of selfed seed in flowers that are equipped for outcrossing. The distinguishing feature of these mechanisms, in terms of the adaptive value of self-pollination, is the timing of the selfing event. Selfing that occurs either before or simultaneous to the arrival of outcross pollen risks preempting ovules, making lower-quality inbred seed at the risk of reducing the number of outcrossed and higher-fitness seed. Preemption or seed discounting (Lloyd 1992) is selectively advantageous under much narrower conditions than selfing that occurs at the end of the flower's life span (Lloyd 1979, 1992). If delayed selfing on any given flower affects resource allocation to future flowers (e.g., Macnair and Cumbes 1990), so that seed discounting is expressed through future lost outcrossing opportunities (Holsinger 1996; Kliber and Eckert 2004), then intermediate levels of delayed selfing will be favored. Ophrys apifera is a delayed selfer, and the same is somewhat true of $T$. chantreiri, because most of the selfing occurs when the dehisced pollen (lying in the bottom of the flowers when the flower is erect) falls onto the stigma as the flowers become pendant. While delayed selfing is intuitively adaptive, we would not expect plants with such extraordinary flowers as $O$. apifera's and T. chantreiri's to either potentially or actually self to such an extent if pollinator specialization is ensuring outcrossing.

What, then, are we to make of these unrelated species with highly elaborate flowers, both of which are actually 
predominantly selfing? Do these species represent a common trend in flowering plants that selfing may accompany pollinator specialization, or are these two flowering species minor deviations from our overall understanding that floral specialization reflects adaptations to ensure outcrossing? What types of breeding systems are associated with autonomous selfing, and what are the mechanisms by which autonomous selfing is achieved?

These questions interface between pollination and mating system biology. Although the two disciplines are inherently related, historically they have developed independently of each another. Extensive reviews of both fields exist (e.g., Faegri and van der Pijl 1979; Barrett 2002; Fenster et al. 2004), and the importance of simultaneously studying both mating and pollination systems has recently been underscored (Harder and Barrett 1996; Holsinger 1996; Barrett 2003). This is unfortunate, because two of the most frequent evolutionary transitions in flowering plants involve the evolution of pollination systems (Fenster et al. 2004; Wilson et al. 2005) and the evolution of selfing from outcrossing mating systems (Stebbins 1974; Fenster and Barrett 1994; Fenster et al. 1995). Furthermore, mixed mating systems, likely reflecting some autonomous selfing, are a common phenomenon of biotic pollination systems (Goodwillie et al. 2005). Unfortunately, systematic surveys focused on determining the importance of reproductive assurance within the context of pollination system evolution do not exist. Given that one of the most frequently invoked adaptive explanations for the evolution of selfing is lack of pollinators (e.g., Hagerup 1951; Faegri and van der Pijl 1977), it behooves us to scrutinize floral mechanisms that ensure selfing in light of pollination biology.

Thus, we have surveyed the literature to determine the uniqueness of Darwin's (1877) and Zhang et al.'s (2005) observations, and we use as a starting point Darwin's hypothesis that reproductive-assurance mechanisms should rarely be found among flowering plants with specialized pollination systems. Given the selective premium for delayed selfing (see above), we also hypothesize that where reproductive-assurance mechanisms are observed, they will be associated with delayed selfing. Our survey builds on and extends those of earlier reviews (Cruden and Lyon 1989; Lloyd and Schoen 1992) that demonstrated the widespread potential of plants to set seed autonomously. We do so while noting both pollination and breeding systems and considering alternative explanations to the fundamental assumption that the evolution of pollination syndromes reflects selection to promote cross-pollination.

\section{Methods}

We conducted a literature survey for plants with autonomous self-fertilization using the search engine ISI Web of Science. We conducted searches using the keywords "autogamy" and "autonomous self-pollination" and a citation search for Lloyd and Schoen (1992), and we examined the literature cited within these articles. We considered only those species for which information on both pollinator visitation and measures of autonomous self-pollination were available (see below). Because we are interested in documenting pollination system and breeding system for species that are facultatively selfing, we attempted to eliminate cleistogamous species by considering flower size, reward, and pollinators. Only nine of the species in our survey had flowers $<10 \mathrm{~mm}$ in length or diameter, and all of these flowers were components of larger blossom displays and/or produced a reward or were frequently visited by pollinators. These nine species were almost equally distributed among specialized and generalized pollination modes (see below for definition), with five having specialized pollination and four having generalized pollination. We did not include species where apomixis has been reported. Species with potential autonomous selfing rates of $<10 \%$ were also excluded from the survey to ensure that contamination was not a source of the presumed selfed seed.

To quantify the extent to which autonomous selfing could act as a fail-safe for lack of pollinator activity and the degree to which flowers with either specialized or generalized pollination systems actually needed to rely on these fail-safe breeding systems, we calculated both the potential and the actual rate of autonomous self-pollination. Potential autonomous selfing rate equals the mean seed or fruit set of caged or bagged flowers divided by the seed or fruit set of open-pollinated flowers. Actual autonomous selfing rate equals one minus the mean seed or fruit set of emasculated, open-pollinated flowers divided by the seed or fruit set of nonmanipulated, open-pollinated flowers: 1 - (emasculated/open). Mean fruit set was used when measures of seed set were not available or when original seed set calculations eliminated fruits that set no seed. Fruit set values may in some cases overestimate potential selfing if the developing fruits from bagged treatments contained a smaller fraction of seeds than that from open pollination treatments. However, it is unlikely that using fruit set values alters our conclusions since fruit set values were used for only seven out of 80 species in our survey (indicated in table 1). The seed set of caged flowers was divided by that of hand cross-pollinated flowers to obtain the potential autonomous selfing rate when an open pollination treatment was not included in the study. The number of pollen grains on the stigma after the different pollination treatments was used in two cases where there were no fruit/seed production data. All deviations from our standard calculations of autonomous self-pollination are indicated in table 1 . We also recorded selfing rates based on genetic markers whenever this information was available (table 2).

To determine whether a species had a generalized or specialized pollination system, we scored all species for pollinators based on the published information and occasionally supplemented the data with unpublished information provided by authors. We then assigned each species to pollinator functional groups (tables 1,3), i.e., pollinators that exert similar selection pressures on flowers because of similarity in behavior on the flower, e.g., large bees or nocturnally flying moths, with pollination by two or more functional groups treated as generalization (Fenster et al. 2004). The use of functional groups is inherent to the idea of pollination specialization, which recognizes that commonality of floral expression reflects commonality of selective pressures mediated by pollinators constituting a functional group (Vogel 1954; Faegri and van der Pijl 1977; Baker and Baker 1983). It is easiest to describe how we assigned pollination specialization or generalization to a plant's pollination system using idealized instances. If two plant species were predominately pollinated 


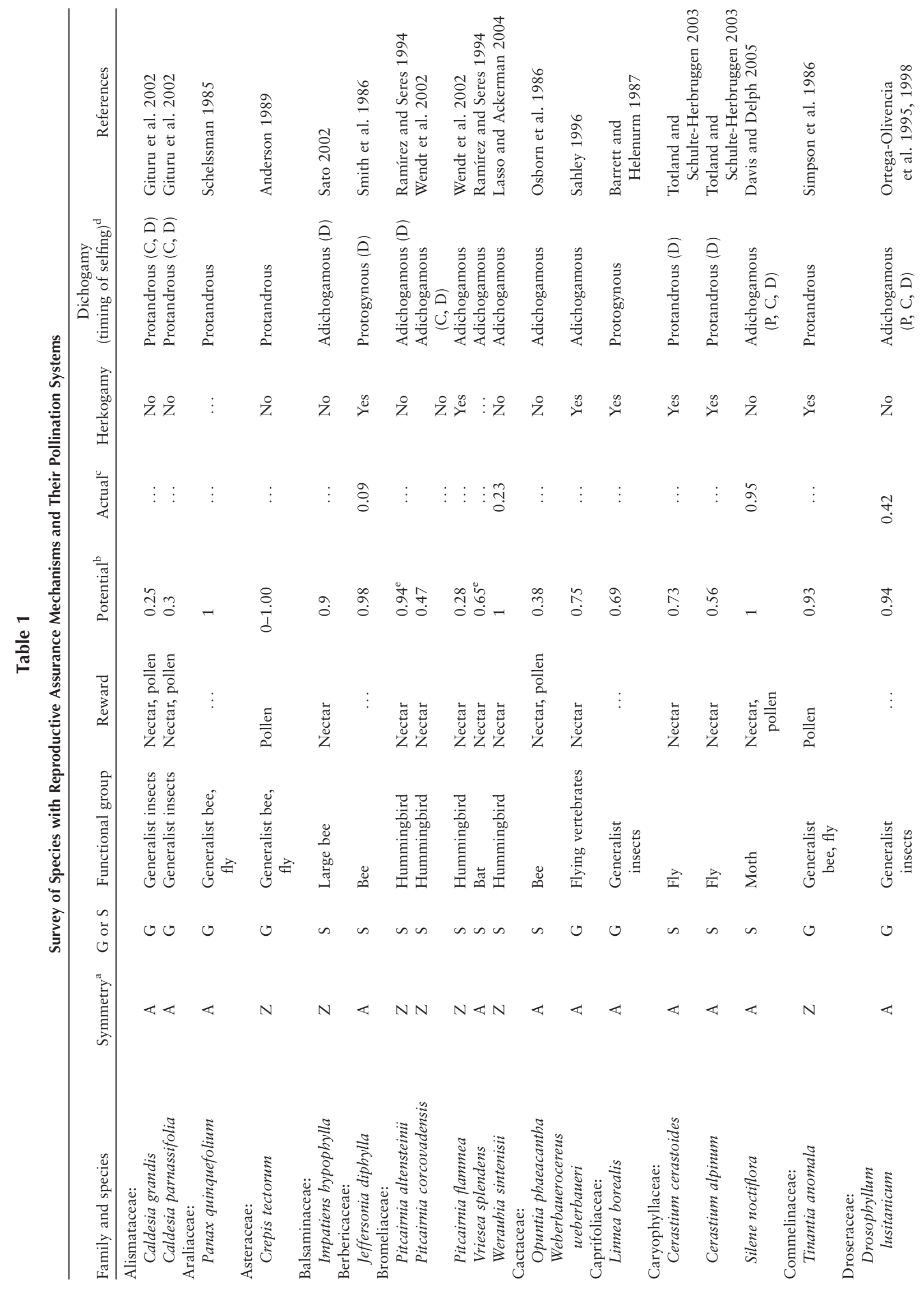




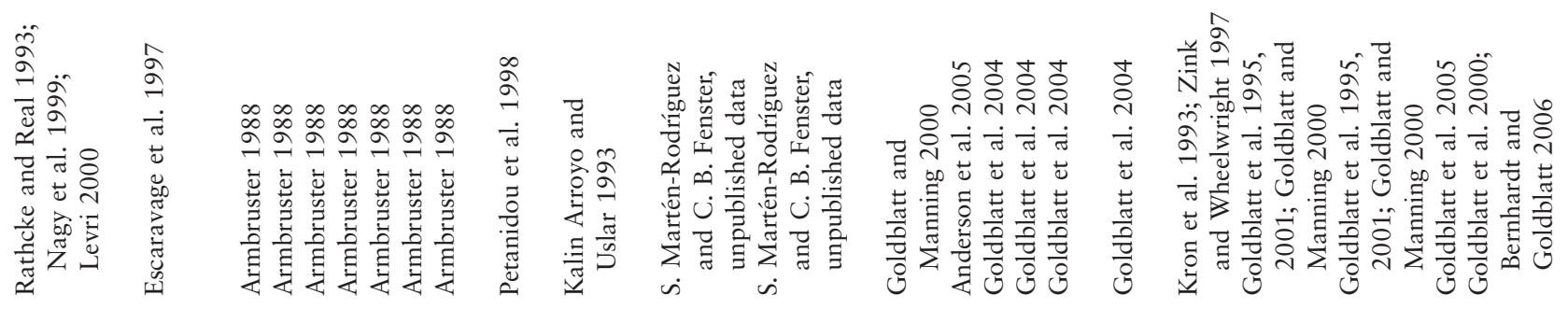

票

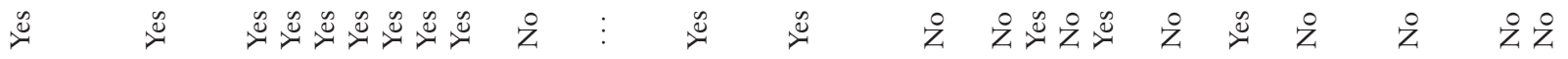

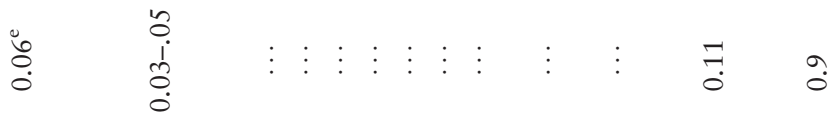

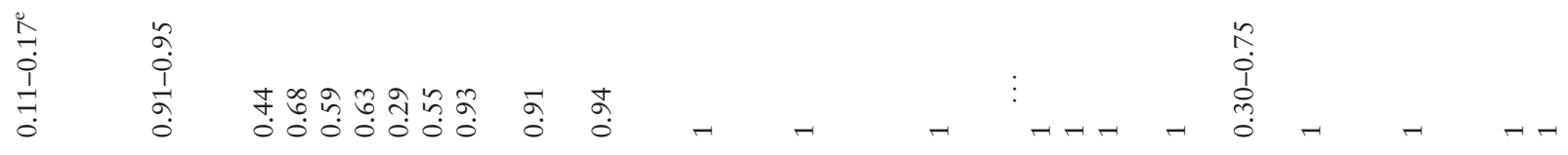

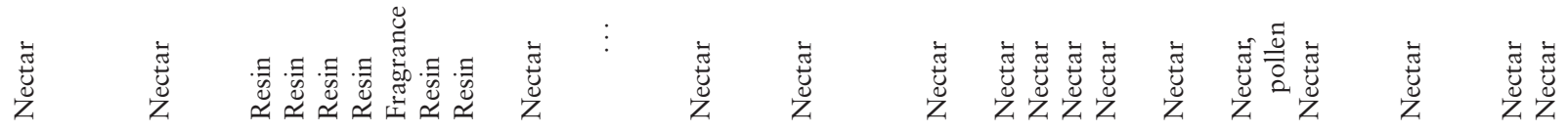

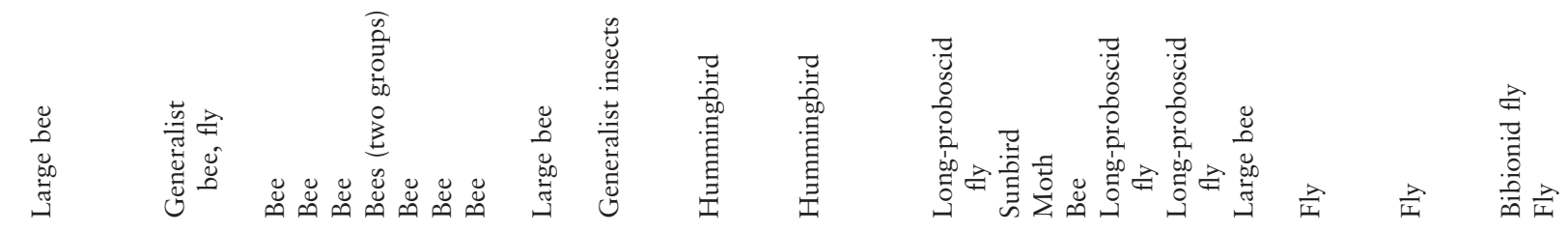

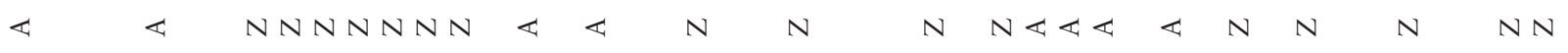

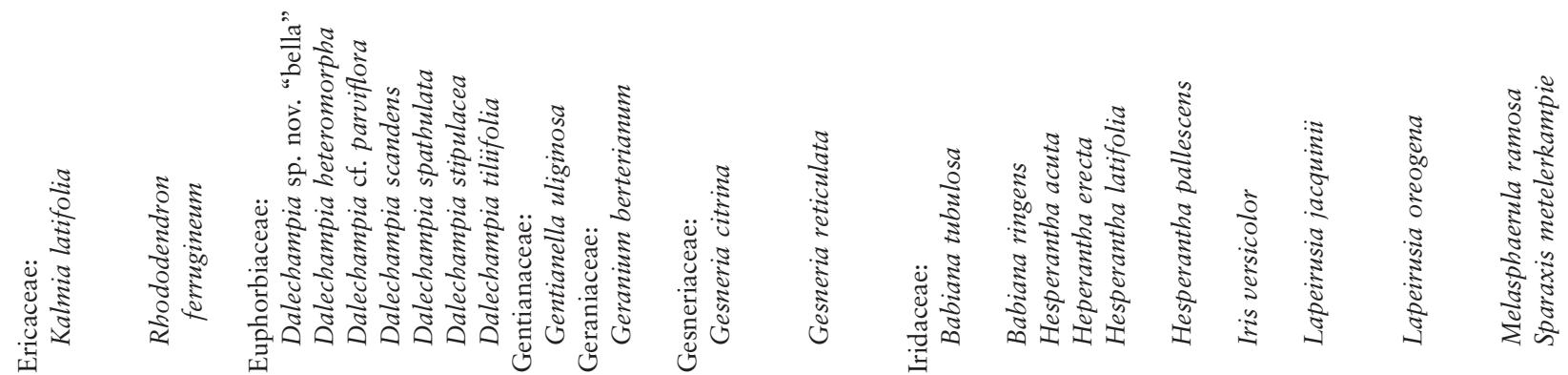




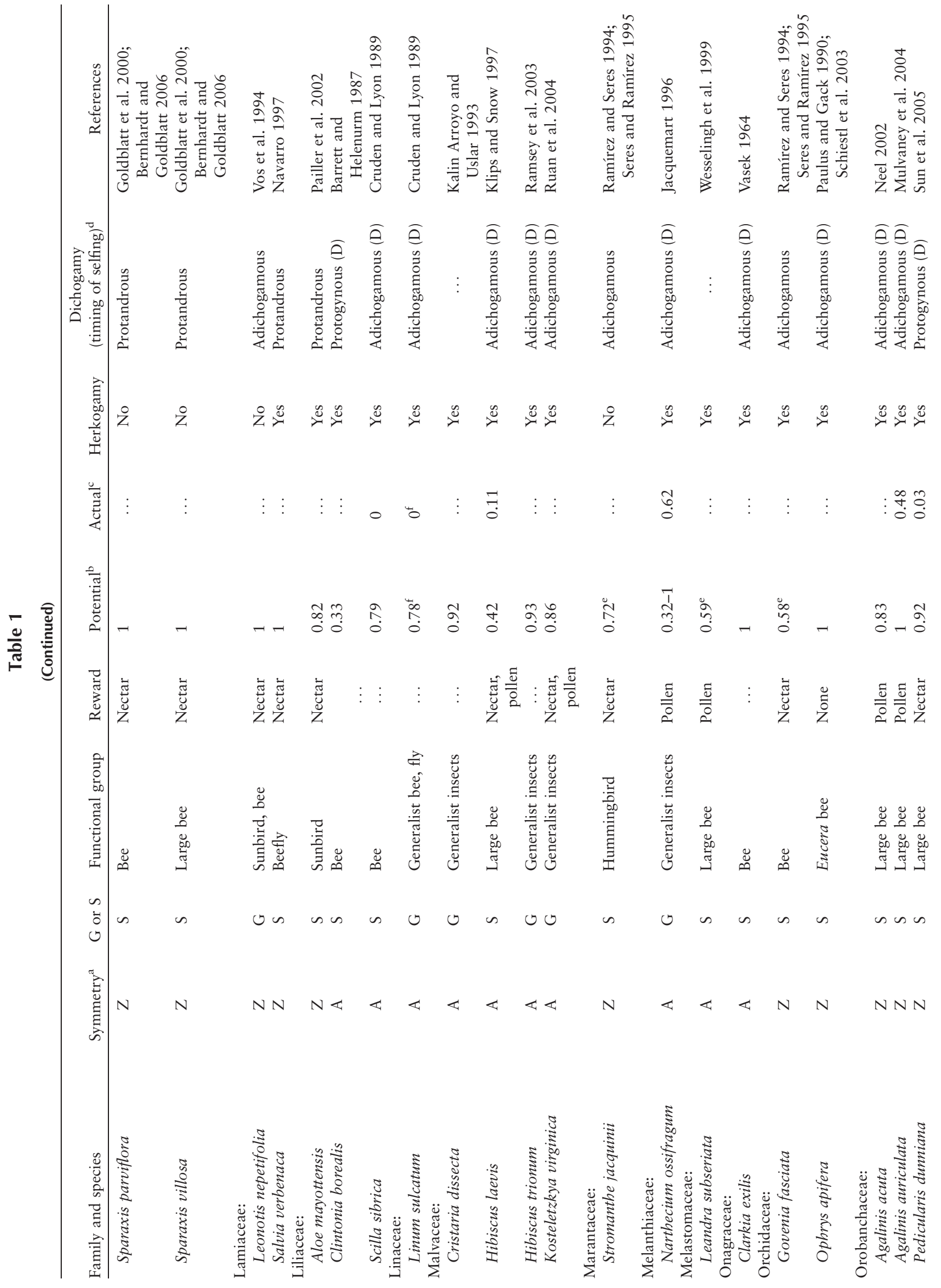




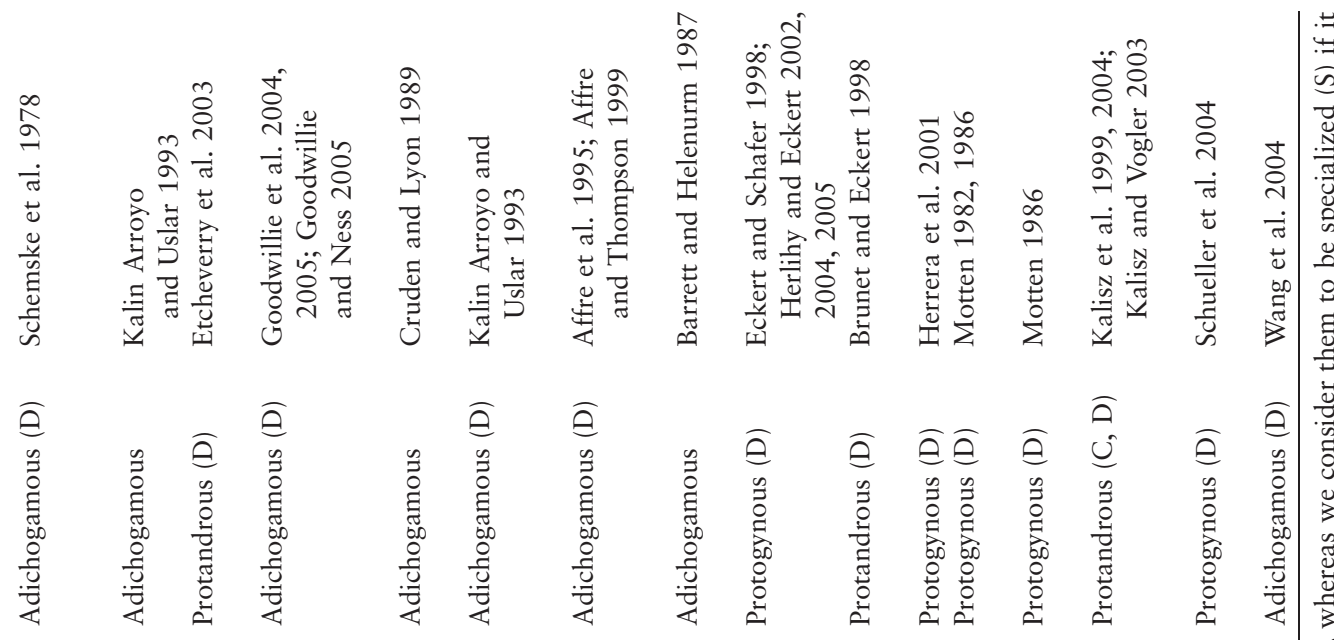

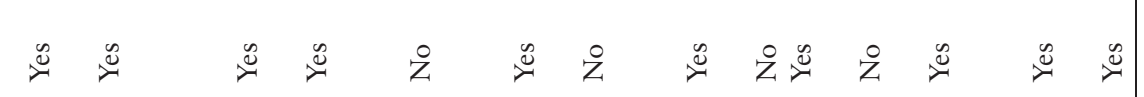
$+\quad \vdots \quad \vdots \quad \vdots \quad \frac{+}{0} \quad \vdots \quad \vdots \stackrel{m}{0} \quad \vdots \quad \frac{\pi}{0}$

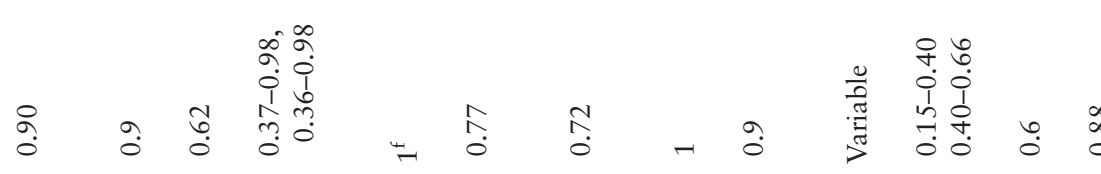

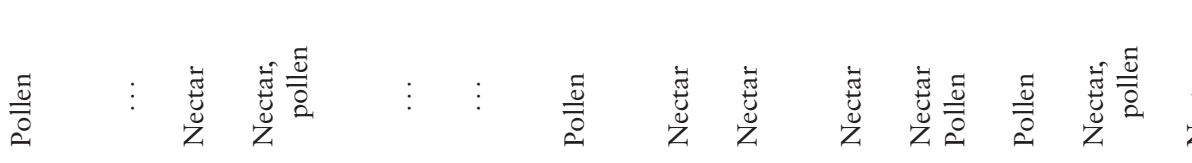

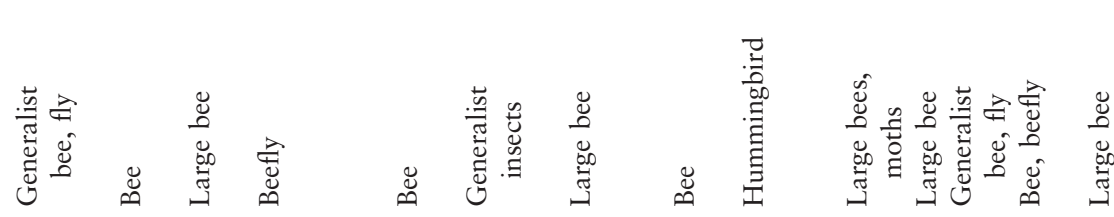

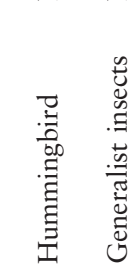
0 in is on

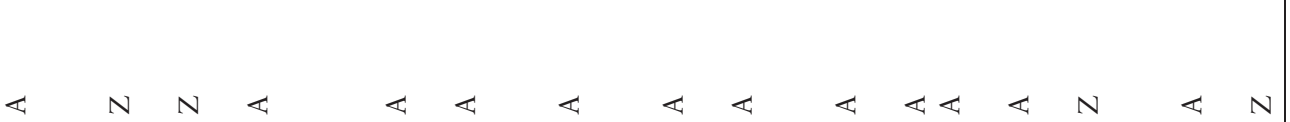
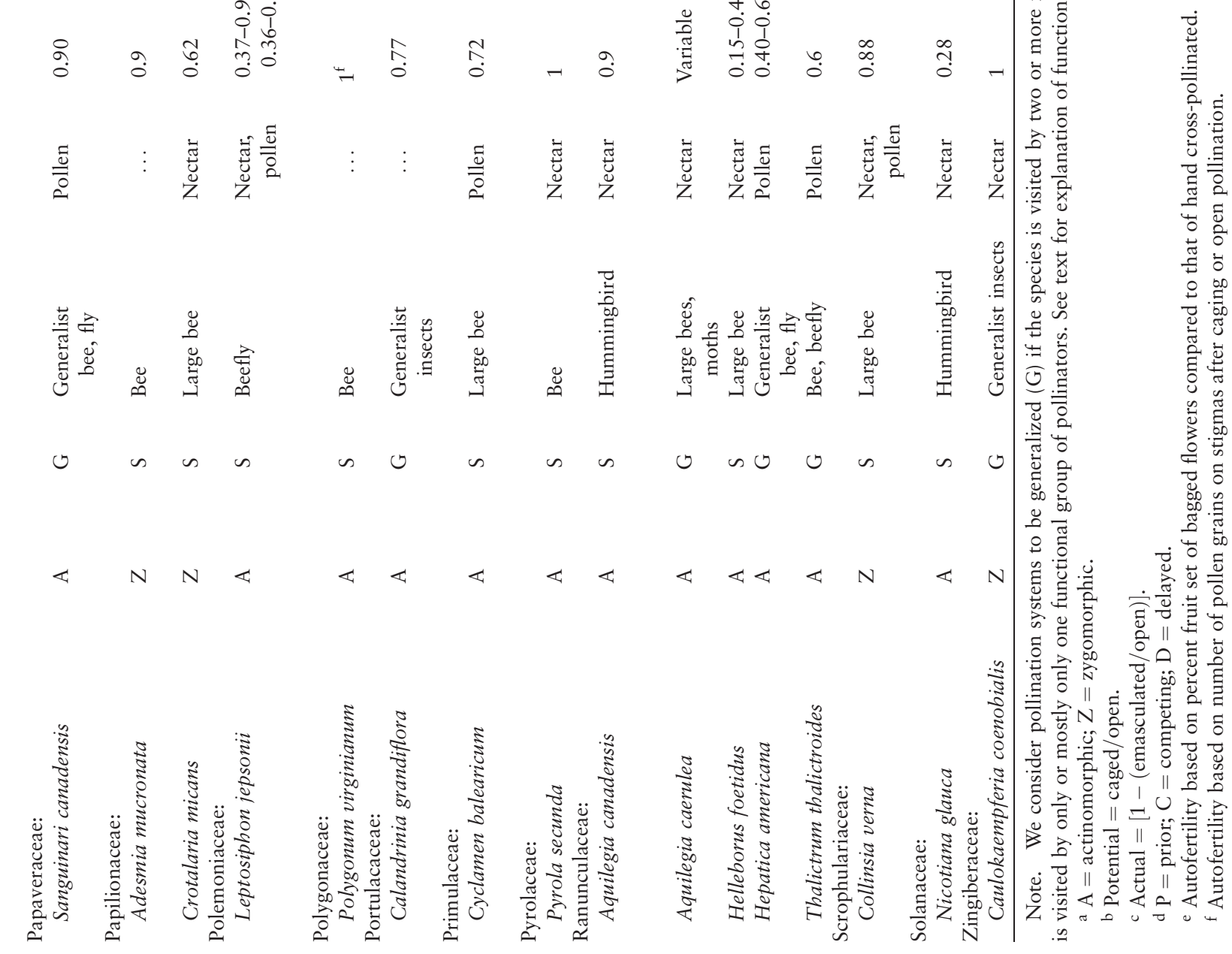
Table 2

Potential Autonomous Selfing Rates Compared to Actual Selfing Rates Derived from Genetic Marker Data for Seven Species

\begin{tabular}{|c|c|c|c|}
\hline Species & Potential & Selfing rate & References \\
\hline Aquilegia canadensis & 0.9 & 0.75 & $\begin{array}{l}\text { Eckert and Schafer 1998; Herlihy } \\
\text { and Eckert 2004, } 2005\end{array}$ \\
\hline Babiana ringens & 0.59 & $0.77^{\mathrm{a}}$ & Anderson et al. 2005 \\
\hline Clarkia exilis & 1 & 0.55 & Vasek 1964 \\
\hline Cyclamen balearicum & $0.72^{\mathrm{a}}$ & Ca. $0.90^{\mathrm{a}}$ & $\begin{array}{l}\text { Affre et al. 1995; Affre } \\
\text { and Thompson } 1999\end{array}$ \\
\hline Kalmia latifolia & $0.11-0.17$ & 0.08 & $\begin{array}{l}\text { Rathcke and Real 1993; Nagy } \\
\text { et al. 1999; Levri } 2000\end{array}$ \\
\hline Leptosiphon jepsonii & $0.36-0.98$ & 0.78 & Goodwillie and Ness 2005 \\
\hline Weberbauerocereus weberbaneri & 0.75 & 0.06 & Sahley 1996 \\
\hline
\end{tabular}

Note. Seed production of pollinator excluded open- or hand-pollinated flowers.

a A selfing rate based on genetic markers higher than the potential selfing rate may reflect selfing occurring through geitonogamy or the broad standard errors commonly associated with selfing rate estimation.

by five species of bumblebees and 20 species of nocturnal moths, respectively, then we scored these two plants as having pollination systems specialized to either bumblebees or nocturnal moths. However, if the investigator demonstrated that both bumblebees and nocturnal moths were important pollinators of the plant, then we scored the plant as having a generalized pollination system. We did not use the functional groups described by Fenster et al. (2004) because the application of functional groups in that paper was to a survey of an Illinois community (Robertson 1928), and here we include studies from around the world.

The total number of hours researchers spent observing pollinators was extremely variable, ranging from as few as six to many hundred hours, with typical observation periods of about a week. Often the amount of time spent observing pollinators on particular plant species corresponded to the frequency of pollinator visits. For species where the frequency of visitation is very high, e.g., many bee-pollinated species, then the effort spent surveying the pollinator fauna was relatively less than in species where the frequency of pollinator visitation was much lower, e.g., many hummingbird-pollinated species. In addition, the type of data collected to quantify visitors as potential pollinators varied. Investigators used visitation frequency, effectiveness of pollen transfer, or both to assign pollinators. We used the investigator's notion of effective pollinators only to distinguish between pollinators and nonpollinating visitors and consequently to assign the plants to functional groups of pollinators that did not include nonpollinating visitors as pollinators. We believe that assignment of plants to specialized pollination systems, i.e., pollinated by one functional group by our criteria, is conservative, because in our experience it is only often after intense study, including quantifying frequency and effectiveness of the pollinators, that one can determine the importance of specific pollinators to a given plant species. Consequently, one is more likely biased toward classifying a plant as having a generalized pollination system until further work is conducted.

In addition to flower size and reward, we scored all species for three additional floral traits thought to be associated with pollinator specialization or the degree of autonomous selfpollination. We scored floral symmetry and the presence and type of dichogamy and herkogamy. Note that we did not use floral traits to define pollination systems, whether specialized or generalized. The observations of the pollinators on the plants by the authors were the sole criteria for assigning a plant's pollination system. We scored breeding systems (dichogamy and herkogamy) to determine whether we could find an association of breeding system with autonomous selfing. In addition, because the timing of autonomous selfing figures prominently in the selective advantage of reproductive assurance, we coded species based on the method of autonomous self-pollination (prior/competing/delayed) and the mechanism by which autonomous self-pollination occurs (e.g., corolla dragging), as described by the authors. Autonomous selfing was assumed to be through delayed selfing in species with protogynous breeding systems. We were able to assess the timing and method of autonomous selfing for only a subset of the species.

\section{Results}

In total, 38 plant families and 80 species spanning many types of pollination systems, from highly specialized to generalized,

Table 3

Number of Species with Autonomous Self-Pollination Systems, Grouped by Pollinator Functional Group and Floral Symmetry

\begin{tabular}{lccr}
\hline Functional group & Actinomorphic & Zygomorphic & Total \\
\hline Bat & 1 & & 1 \\
Bee & 14 & 18 & 32 \\
Beefly & 1 & 1 & 2 \\
Fly & 4 & 5 & 9 \\
Hummingbird & 2 & 7 & 9 \\
Moth & 2 & 2 & 2 \\
Sunbird & & 1 & 2 \\
Generalist bee & 17 & 3 & 20 \\
Insect generalist & & & \\
Flying vertebrate (bird and & 1 & & 1 \\
$\quad$ bat, i.e., generalist) & & 1 & 1 \\
Other generalist & & 38 & 80 \\
$\quad$ Total & 42 & & \\
\cline { 2 - 4 }
\end{tabular}


are represented in our survey. A list of pollination systems, breeding systems, and measures of autonomous selfing for the surveyed species is presented in table 1 . All species for which we had information on the timing of selfing ( 38 species; table 1) exhibited delayed selfing, while only six of these 38 species had accompanying prior and/or competing selfing.

When assessing the association between specialization and floral symmetry, we found that of 42 species with actinomorphic flowers, 18 had generalized pollination systems, whereas of 38 species with zygomorphic flowers, only five had generalized pollination systems (table 3 ). Thus, we find that zygomorphy is associated with specialization $\left(\chi^{2}=8.59, \mathrm{df}=1, P<0.01\right)$.

Our overall sampling method does not allow us to assess whether pollination specialization is more likely than pollination generalization to be associated with autonomous breeding systems. Nonetheless, we are able to evaluate this issue, using the four community-level surveys that contributed to our data set to test for an association between pollination specialization and autonomous breeding systems. Thus, when we compare autonomous with nonautonomous species from the surveys of temperate deciduous forest (Schemske et al. 1978; Motten 1986), boreal forest (Barrett and Helenurm 1987), and Venezuelan cloud forest (Ramírez and Seres 1994), we detect no association of pollination specialization with autonomous breeding systems $(37.5 \%$ of eight species with generalized pollination and $33.3 \%$ of 24 species with specialized pollination have the ability to autonomously self; $\left.\chi^{2}=0.046, \mathrm{df}=1, P>0.80\right)$.

The frequency of dichogamy and herkogamy in species capable of autonomous self-pollination is shown in table 4. There was no association between the occurrence of autonomous breeding systems and the absence of herkogamy or dichogamy $\left(\chi^{2}=0.002, \mathrm{df}=1, P>0.90\right)$. Sixty-three percent of documented species have herkogamous flowers, while $59 \%$ of species for which we could obtain this information exhibited some form of dichogamy (table 4). There were 11 species in our survey that did not exhibit dichogamy or herkogamy; these had medium to large flowers and specialized pollination systems.

Based on comparisons between emasculated and bagged flowers, observed rates of autonomous selfing (i.e., natural pollination minus emasculation) are significantly lower than potential selfing rates (table 1 ; mean potential of 0.79 vs. mean actual of 0.31 ; paired $t$-test: $t=6.54, \mathrm{df}=18, P<0.0001)$. Selfing rates based on seed set for bagged flowers and selfing rates based on genetic markers are not significantly different

\section{Table 4}

Frequency of Dichogamy and Herkogamy in Species Capable of Autonomous Self-Pollination

\begin{tabular}{lccc}
\hline & Herkogamous & Nonherkogamous & Total \\
\hline Adichogamous & 19 & 11 & 30 \\
Protandrous & 12 & 13 & 25 \\
Protogynous & 15 & 3 & 18 \\
\cline { 2 - 4 }$\quad$ Total & 46 & 27 & 73 \\
\hline
\end{tabular}

Note. There are five species in the survey for which we have an incomplete description of the breeding system and one species with no description of the breeding system. (table 2; mean potential of 0.68 vs. mean selfing rate of 0.56 ; Wilcoxon signed-rank test, seven comparisons).

\section{Discussion}

Our survey was stimulated by Zhang et al.'s (2005) observation that in the flower of Tacca chantieri there are "confounding" floral traits, with some features conforming to the highly specialized pollination syndrome associated with sapromyiophily while others facilitate mating via autonomous selfing. Like T. chantieri, other species with showy flowers exhibit highly selfing mating systems and a conspicuous absence of floral visitors, e.g., the orchid Oeceoclades maculata (Gonzalez-Diaz and Ackerman 1988) and the ginger Caulokaempferia coenobialis (Wang et al. 2004). These cases may reflect a loss of specialized pollinators due to habitat degradation (Wagner et al. 2005; e.g., Schiedea lychnoides, presumably pollinated by extinct honeyeaters), and perhaps further observations in other parts of the species' ranges may reveal pollinators conforming to the predicted syndrome. However, it is likely that most of the 80 species with autonomous breeding systems included in our survey have functional pollination systems, including the 57 species that were categorized as specialists. Hence, we conclude that floral mechanisms that facilitate autonomous seed set are frequently associated with specialized pollination systems (table 1).

Many types of pollination systems, from highly specialized to generalized, are represented in our survey. Seventy-one percent of the 80 species recorded have specialized pollination systems, and most are medium-to-large-flowered species that provide nectar and/or pollen rewards as well as more specialized resin or fragrance rewards. These floral traits suggest that these species are capable of high outcrossing rates under certain pollinator environments, in addition to being facultative selfers. The predominant mode of autonomous selfing documented in our survey is delayed selfing. All species for which we had information on the timing of selfing exhibited delayed selfing, while only seven species had accompanying prior and/or competing selfing, suggesting that delayed selfing is frequently an important mechanism of reproductive assurance in species with either generalized or highly specialized pollination systems.

The signal of pollinator specialization is reflected in the distribution of specialized versus generalized pollination across species with either actinomorphic or zygomorphic floral symmetry patterns. Thus, we find that zygomorphy is associated with specialization (table 3), as observed in other large surveys (Faegri and van der Pijl 1977; Fenster et al. 2004). There is some controversy in the literature as to the relevance of pollinator specialization, in large part associated with the differing care observers take in distinguishing pollinators from nonpollinating visitors or important pollinators from casual pollinators (Waser et al. 1996; Fenster et al. 2004). However, we think that the association of zygomorphy with pollinator specialization in our survey provides a sense of quality for our survey data. Furthermore, the pollinator observations for the species often did conform to expectations based on the pollination syndrome concept; e.g., bird-pollinated species had brightly colored tubular flowers with rich nectar rewards. In contrast to an earlier survey by 
Lloyd and Schoen (1992), we observed a considerable number of species with zygomorphic flowers among species that have the ability to set seed without pollinators.

Species with specialized pollination systems also having a reproductive-assurance mechanism suggests that one of the proposed selective forces acting against pollination specialization may be overcome. A corollary of Waser et al.'s (1996) theoretical result is that pollination specialization results in a greater variance of reproductive success and attendant reproductive failure. The assumption is that generalized pollination systems are buffered from the fluctuations of individual pollinator species or functional groups. Accordingly, pollination generalization is more likely to reflect the optimal state. However, our survey demonstrates that plants can evolve floral features that promote pollination specialization and reproductive assurance, and it is likely these character states can evolve independently, since there are many cases of plants having specialized pollination systems yet no ability to set seed autonomously.

Our sampling does not allow us to state unequivocally that pollinator specialization is more or less likely to be associated with reproductive-assurance mechanisms, because we biased our sampling toward those species that have autonomous selfing. More explicitly, although $71 \%$ of species in our survey of plants with reproductive-assurance mechanisms have specialized pollination systems, we cannot state that the evolution of specialized pollination systems is more likely to be associated with the evolution of reproductive-assurance mechanisms. Rather, it is likely that most pollination ecologists focus their attention on species that a priori have specialized pollination systems. If species with specialized pollination systems do receive more attention, then a survey of species with described pollination systems also having reproductive-assurance mechanisms will also include more species with specialized pollination systems. Ideally, we would like to conduct an analysis of phylogenetically independent contrasts of pollination and breeding systems to determine whether pollination specialization is more or less likely to be associated with the evolution of autonomous selfing. Unfortunately, such information is not yet available. However, the survey does allow us to make some inference about the co-occurrence of pollination and breeding systems. When we restricted the comparison of autonomous and nonautonomous species to the four communitylevel surveys that contributed to our data set, we found no association of pollination specialization with autonomous breeding systems. Presumably, these studies represent an unbiased sampling of flowers with specialized and generalized pollination systems. Thus, our survey suggests that pollinator specialization does not preclude the evolution of floral mechanisms that facilitate autonomous self-pollination and that autonomous self-pollination is as likely in specialized as in generalized pollination systems.

We conclude that pollination and breeding system evolution need not be linked and may reflect independent selective forces, as first noted by Armbruster (1988) in his studies of tropical Dalechampia. Thus, the dilemma faced by plants with specialized pollination systems, that they are prone to reproductive failure (Morgan and Wilson 2005), may be solved by the evolution of reproductive-assurance mechanisms. The bet-hedging strategy of evolving reproductive-assurance mechanisms forces us to think differently about what might appear to be obligate pollination systems. Future studies of floral biology must simultaneously document pollination and breeding systems because the preconceived notion that pollinator specialization is exclusively associated with outcrossing is clearly false. We also need to know whether plants with specialized pollination systems suffer greater variance of outcrossing pollination success (Waser et al. 1996). If so, then the important question is whether the evolution of reproductiveassurance mechanisms accompanies the evolution of pollination specialization. Alternatively, plants with generalized pollination systems may be more likely to exhibit accompanying selfing because of the less predictable movements of pollinators within the flower (Schoen and Lloyd 1992). Hopefully, comparative approaches utilizing the mapping of breeding and pollination systems on well-supported phylogenies will allow us to address these important questions.

Autonomous selfing is associated with both modes of intrafloral dichogamy (protandry and protogyny) and varying herkogamy levels. Sixty-three percent of documented species have herkogamous flowers with sundry mechanisms to bring the reproductive organs together, usually toward the end of the flower's life, e.g., corolla dragging in Agalinis and Kalmia (fig. 1C); stigma movement toward the anthers in Clarkia, Collinsia, Iris, Malvaceae (fig. 1D, 1E), and Gesneria (fig. 1F, $1 G)$; and anther movement toward the stigma in Jeffersonia and Tinantia. The variety of mechanisms leading to reproductive assurance is exemplified by the genus Collinsia, where autonomous selfing is achieved by a variety of developmental mechanisms (Armbruster et al. 2002). Even where herkogamy and dichogamy are absent in the species in our survey, the flowers are not obligate selfers, and their floral traits reflect evolution for pollinator specialization. This is also implied by the low potential rates of autonomous selfing or the much lower actual than potential selfing rates in some of the adichogamous and nonherkogamous species (e.g., Drosophyllum lusitanicum, Opuntia phaeacantha, and Werauhia sintenisii). Given that we have only one estimate of mating system among the 11 species lacking both herkogamy and dichogamy, it is difficult to determine the consequences of these breeding systems in terms of actual selfing rate. The lack of data demonstrates the necessity for collecting mating system estimates along with descriptions of breeding and pollination systems.

Dichogamy is common in species with autonomous breeding systems, and protandry is more common than protogyny. Protogyny is expected to be a more efficient mechanism of reproductive assurance than protandry, since protogynous flowers can self-pollinate at the end of the female phase if outcrossing is not achieved (Mallick 2001). Thus, one might expect a priori that the protogynous breeding system is more associated with delayed autonomous selfing. However, protandry may serve as an efficient autonomous selfing mechanism in the absence of pollinators if the presence of unremoved pollen in the anthers serves as a bioindicator or predictor of limited pollinator activity (Mallick 2001). Protandry is twice as common as protogyny in our survey (when protogynous and monoecious Dalechampia that have multiple male and female flowers organized into blossoms are not included in the analysis), consistent with the observation that protandry is the most common mode of dichogamy in the flowering plants (Bertin and Newman 1993). 
Our sample sizes prevent us from making overarching statements concerning the adaptive significance of one mode of dichogamy versus the other. However, all 12 species exhibiting protogyny (Aquilegia, Clintonia, Gesneria [two species], Hepatica, Helloborous, Jeffersonia, Linnea, Nicotiana, Pedicularis, Sanguinaria, Thalictrum) appear to flower in environments having extreme spatial or temporal variation and consequently unpredictable pollinator activity from day to day and even hour to hour. Sometimes the visitation rates to these species are extremely low (e.g., Gesneria, Pedicularis, and Helloborus), which would contribute to great variation in pollinator service. Further illustrative of this point are Sanguinaria canadensis and Aquilegia canadensis (fig. 1H). Sanguinaria canadensis is among the earliest flowering spring ephemerals in the North American deciduous forest, and its 2-d flowers experience fluctuating temperatures on the cusp of tolerance for flying insects (Schemske et al. 1978; Motten 1986). Aquilegia canadensis shows great variability in the degree of autonomous selfing that may reflect spatial variability in pollinator service and population variability in herkogamy (Herlihy and Eckert 2002, 2004). Broad surveys of dichogamy in angiosperms found that alpine species are predominately protogynous (Bertin and Newman 1993), as are wind-pollinated species (Sargent and Otto 2004), congruent with the notion that where there is little correlation between pollen removal during one time period and pollen receipt in another, protogyny is favored for reproductive assurance.

Despite its widespread occurrence, the observed levels of autonomous selfing appear to be much lower than the potential to set seed without pollinators. However, selfing rates based on seed set for bagged flowers and those based on genetic markers are not significantly different (table 2), likely reflecting the small sample size and perhaps the contribution of biparental inbreeding to open-pollinated flowers. That actual autonomous seed set is often lower than the potential for autonomous seed set is evidence that the selfing we have documented here actually functions as reproductive assurance or as a fail-safe mechanism for species with either generalized or specialized pollination systems. Nonetheless, the $56 \%$ rate of actual autonomous selfing (table 2) strengthens the notion that seed set is frequently limited by outcrossed pollen. Two elegant studies experimentally confirm the benefits of autonomous selfing in bee-pollinated Collinsia verna (Kalisz and Vogler 2003; Kalisz et al. 2004) and hummingbird-pollinated A. canadensis (Herlihy and Eckert 2002, 2004). In these fieldbased studies, the investigators demonstrated that autonomous selfing increased when pollinator activity decreased.

There is ample evidence that pollinator activity can be variable at both population (Fenster 1991a; Fenster and Dudash 2001) and community levels (Primack and Inouye 1993); thus, it may not be surprising that reproductive-assurance mechanisms are found in both generalized and specialized pollination systems. The widespread occurrence of reproductiveassurance mechanisms that we document here mirrors the results of another recent review, where reproductive assurance mechanisms are found in species across a wide spectrum of outcrossing rates (Goodwillie et al. 2005). Thus, whether species are highly outcrossing or less so, they maintain the ability to set seed in the absence of pollinators. However, this begs the question, why evolve pollination specialization if it does not ensure seed set through outcrossing? Below, we suggest possible selective forces underlying the evolution of specialized pollination systems. These possible selection scenarios incorporate the history of selection for reproductive assurance, reflected in the evolved "contrivances" associated with autonomous selfing that are found even among species with highly specialized pollination systems.

The survey underscores the omnipresence of pollen limitation across pollination systems (Knight et al. 2005). Thus, the lability of pollination systems, even among closely related species and indeed pollination ecotypes (Fenster et al. 2004), may reflect selection to reduce pollen limitation, in other words, to increase female reproductive success. Given the specific environmental context, we conjecture that pollen limitation will favor evolutionary shifts in pollination systems from generalized to specialized, from specialized to generalized, and from specialized to differently specialized pollination systems. That is, no matter what the pollination system is, a species, at least in some part of its geographic range, during some component of its evolutionary history, is likely to experience pollinator limitation, perhaps resulting in selection on floral traits to attract alternative pollinators or to attract additional pollinators. Indeed, a previous review demonstrated that pollen limitation is found in species exhibiting pollinator specialization and pollinator generalization (Larson and Barrett 2000), and the most inclusive review of pollen limitation conducted to date (Knight et al. 2005) found that pollen limitation was negatively associated with the number of pollinators per plant species (classified as one, few, or many), so that taxa with many pollinators experienced less pollen limitation. Thus, transitions between pollination systems may reflect constant selection to increase or maintain female reproductive success. Alternatively, selection acting through male reproductive success may favor pollination specialization. Thus, specialized pollination systems may have increased pollen transfer efficiency (Inouye et al. 1994) relative to related species with generalized pollination. We have very little understanding of the selective forces that mediate pollination system evolution, and we clearly need more studies that do so (Fenster et al. 2004).

Because selfed seeds often manifest inbreeding depression (e.g., Fenster 1991b; Fenster and Galloway 2000), the seeds produced by autonomous selfing may contribute limited fitness benefit. When autonomously produced seeds in one flower reduce resources available for potential outcrossed seed in later flowers on the plant, as in the case of A. canadensis (Herlihy and Eckert 2002, 2004), seed discounting as a consequence of extreme inbreeding depression drastically reduces the benefit gained through delayed selfing, obscuring the adaptive significance of autonomous selfing in the populations studied. Future research should focus on the phenomenon of seed discounting to quantify the adaptive gain of autonomous selfing in the face of inbreeding depression.

In the "Introduction," we focused on the need to combine mating, breeding, and pollination system studies in order to have a better understanding of the forces underlying floral diversification of the angiosperms, a point also made earlier by others (Harder and Barrett 1996; Holsinger 1996). By considering all three aspects of floral biology, as illustrated in this survey, we demonstrate that traits associated with reproductive 
assurance are important targets of selection, regardless of the pollination system. Consequently, our understanding of processes underlying the evolution of pollination specialization must incorporate other selective forces in addition to placing a premium on high maternal outcrossing.

\section{Acknowledgments}

The ideas for this manuscript were first precipitated in a symposium on coevolution organized by Q.-J. Li and C.-Z. Wang of the Chinese Academy of Sciences. We are grateful to S. Armbruster, M. Ayasse, S. Barrett, A. Dafni, S. Davis,
C. Eckert, P. Goldblatt, C. Goodwillie, S.-Q. Huang, S. Johnson, R. Klips, J. Larrucea, Q.-J. Li, U. Molau, E. Nagy, R. Neiland, G. Oostermeijer, A. Snow, and Ø. Totland for sharing their insights and, in some cases, data sets, which helped illuminate the relationship between pollination and breeding system evolution. J. Cresswell, M. Dudash, R. Reynolds, M. Ruddat, M. Rutter, and two anonymous reviewers provided helpful comments on a previous version of the manuscript. This work was supported by National Science Foundation grant 0108285 to C. Fenster and funds from Sigma-Xi, Graduate Women in Science, American Gloxinia and Gesneriad Society, and the University of Maryland to S. Martén-Rodríguez.

\section{Literature Cited}

Affre L, JD Thompson 1999 Variation in self-fertility, inbreeding depression and levels of inbreeding in four Cyclamen species. J Evol Biol 12:113-122.

Affre L, JD Thompson, M Debussche 1995 The reproductive biology of the Mediterranean endemic Cyclamen balearicum Wilk. (Primulaceae). Bot J Linn Soc 111:309-330.

Anderson B, WW Cole, SCH Barrett 2005 Specialized bird perch aids cross-pollination. Nature 435:41-42.

Anderson S 1989 The evolution of self-fertility in Crepis tectorum (Asteraceae). Plant Syst Evol 168:227-236.

Armbruster WS 1988 Multilevel comparative analysis of the morphology, function and evolution of Dalechampia blossoms. Ecology 69:1746-1761.

Armbruster WS, CPH Mulder, BG Baldwin, S Kalisz, B Wessa, H Nute 2002 Comparative analysis of late floral development and mating-system evolution in tribe Collinsieae (Scropulariaceae s.1.). Am J Bot 89:37-49.

Baker HG, I Baker 1983 Floral nectar sugar constituents in relation to pollinator type. Pages 117-141 in CE Jones, RJ Little, eds. Handbook of experimental pollination biology. Van Nostrand Reinhold, New York.

Barrett SCH 2002 The evolution of plant sexual diversity. Nat Rev Genet 3:274-284.

2003 Mating strategies in flowering plants: the outcrossingselfing paradigm and beyond. Philos Trans R Soc B Biol Sci 358: 991-1004.

Barrett SCH, K Helenurm 1987 The reproductive biology of boreal forest herbs. 1. Breeding systems and pollination. Can J Bot 65:20362046.

Bernhardt P, P Goldblatt 2006 The role of phylogenetic constraints in the evolution of pollination mechanisms in the Iridaceae of sub-Saharan Africa. Pages 434-444 in JT Columbus, EA Friar, JM Porter, LM Prince, MG Simpson, eds. Monocots: comparative biology and evolution. Vol 1. Rancho Santa Ana, Claremont, CA.

Bertin RI, CA Newman 1993 Dichogamy in angiosperms. Bot Rev 59:112-152.

Brunet J, CG Eckert 1998 Effects of floral morphology and display on outcrossing in blue columbine, Aquilegia caerulea (Ranunculaceae). Funct Ecol 12:596-606.

Cruden RW, DL Lyon 1989 Facultative xenogamy: examination of a mixed mating system. Pages 171-207 in JH Bock, YB Linhart, eds. The evolutionary ecology of plants. Westview, Boulder, CO.

Dafni A 1987 Pollination in Orchis and related genera: evolution from reward to deception. Pages 80-104 in J Arditti, ed. Orchid biology: reviews and perspectives. Vol 4. Cornell University Press, Ithaca, NY.

Darwin C 1877 The various contrivances by which orchids are fertilized by insects. 2nd ed. Appleton, New York. 300 pp.
Davis SL, LF Delph 2005 Prior selfing and gynomonoecy in Silene noctiflora L. (Caryophyllaceae): opportunities for enhanced outcrossing and reproductive assurance. Int J Plant Sci 166:475-480.

Eckert CG, A Schafer 1998 Does self-pollination provide reproductive assurance in Aquilegia canadensis (Ranunculaceae)? Am J Bot 85:919-924.

Escaravage N, A Pornon, B Doche, I Till-Bottraud 1997 Breeding system in an alpine species: Rhododendron ferrugineum L. (Ericaceae) in the French northern Alps. Can J Bot 75:736-743.

Etcheverry AV, JJ Protomastro, C Westerkamp 2003 Delayed autonomous self-pollination in the colonizer Crotalaria micans (Fabaceae: Papilionoideae): structural and functional aspects. Plant Syst Evol 239:15-28.

Faegri K, L van der Pijl 1979 The principles of pollination ecology. Pergamon, Oxford. 244 pp.

Fenster CB 1991a Gene flow in Chamaecrista fasciculata (Leguminosae). I. Gene dispersal. Evolution 45:398-409.

$1991 b$ Gene flow in Chamaecrista fasciculata (Leguminosae). II. Gene establishment. Evolution 45:410-422.

Fenster CB, WS Armbruster, JD Thomson, P Wilson, MR Dudash 2004 Pollination syndromes and floral specialization. Annu Rev Ecol Evol Syst 35:375-403.

Fenster CB, SCH Barrett 1994 Inheritance of mating-system modifier genes in Eichhornia paniculata (Pontederiaceae). Heredity 72: 433-445.

Fenster CB, PK Diggle, K Ritland, SCH Barrett 1995 The genetics of floral development differentiating two species of Mimulus. Heredity 74:258-266.

Fenster CB, MR Dudash 2001 Spatiotemporal variation in the role of hummingbirds as pollinators of Silene virginica (Cariophyllaceae). Ecology 82:844-851.

Fenster CB, LF Galloway 2000 Population differentiation in an annual legume: genetic architecture. Evolution 54:1157-1172.

Gituru WR, QF Wang, Y Wang, YH Guo 2002 Pollination ecology, breeding system, and conservation of Caldesia grandis (Alismataceae), an endangered marsh plant in China. Bot Bull Acad Sin 43:231-240.

Goldblatt P, JC Manning 2000 The long-proboscid fly pollination system in southern Africa. Ann Mo Bot Gard 87:146-170.

Goldblatt P, JC Manning, P Bernhardt 1995 Pollination biology of Lapeirousia subgenus Lapeirousia (Iridaceae) in Southern Africa: floral divergence and adaptation for long-tongued fly pollination. Ann Mo Bot Gard 82:517-534.

__ 2000 Adaptive radiation of pollination mechanisms in Sparaxis (Iridaceae: Ixioideae). Adansonia 22:57-70.

2001 Radiation of pollination systems in Gladiolus (Iridaceae: Crocoideae) in southern Africa. Ann Mo Bot Gard 88: 713-734. 
2005 The floral biology of Melasphaerula (Iridaceae: Crocoideae): is this monotypic genus pollinated by march flies (Diptera: Bibionidae)? Ann Mo Bot Gard 92:268-274.

Goldblatt P, I Nanni, P Bernhardt, JC Manning 2004 Floral biology of Hesperantha (Iridaceae: Crocoideae): how minor shifts in floral presentation change the pollination system. Ann Mo Bot Gard 91: 186-206.

Gonzalez-Diaz N, JD Ackerman 1988 Pollination, fruit set, and seed production in the orchid, Oeceoclades maculata. Lindleyana 3: 150-155.

Goodwillie C, S Kalisz, CG Eckert 2005 The evolutionary enigma of mixed mating systems in plants: occurrence, theoretical explanations, and empirical evidence. Annu Rev Ecol Evol Syst 36: 46-79.

Goodwillie C, JM Ness 2005 Correlated evolution in floral morphology and the timing of self-compatibility in Leptosiphon jepsonii (Polemoniaceae). Int J Plant Sci 166:741-751.

Goodwillie C, KL Partis, JW West 2004 Transient self-incompatibility confers delayed selfing in Leptosiphon jepsonii (Polemoniaceae). Int J Plant Sci 165:387-394.

Hagerup O 1951 Pollination in the Faroes-in spite of rain and poverty of insects. K Dan Vidensk Selsk Biol Medd 18:1-48.

Harder LD, SCH Barrett 1996 Pollen dispersal and mating patterns in animal-pollinated plants. Pages 140-190 in DG Lloyd, SCH Barrett, eds. Floral biology. Chapman \& Hall, New York.

Herlihy CR, CG Eckert 2002 Genetic cost of reproductive assurance in a self-fertilizing plant. Nature 416:320-323.

2004 Experimental dissection of inbreeding and its adaptive significance in a flowering plant, Aquilegia canadensis (Ranunculaceae). Evolution 58:2693-2703.

- 2005 Evolution of self-fertilization at geographical range margins? a comparison of demographic, floral, and mating system variables in central vs. peripheral populations of Aquilegia canadensis (Ranunculaceae). Am J Bot 92:744-751.

Herrera CM, AM Sanchez-Lafuente, M Medrano, J Guitian, X Cerda, P Rey 2001 Geographical variation in autonomous self-pollination levels unrelated to pollinator service in Helleborus foetidus (Ranunculaceae). Am J Bot 88:1025-1032.

Holsinger KE 1996 Pollination biology and the evolution of mating systems in flowering plants. Evol Biol 29:107-149.

Inouye DW, DE Gill, MR Dudash, CB Fenster 1994 A model and a lexicon for pollen fate. Am J Bot 12:1517-1530.

Jacquemart AL 1996 Selfing in Narthecium ossifragum (Melanthiaceae). Plant Syst Evol 203:99-110.

Kalin Arroyo M, P Uslar 1993 Breeding systems in a temperate Mediterranean-type climate montane sclerophyllous forest in central Chile. Bot J Linn Soc 111:83-102.

Kalisz S, DW Vogler 2003 Benefits of autonomous selfing under unpredictable pollinator environments. Ecology 84:29282942.

Kalisz S, DW Vogler, B Fails, M Finer, E Shepard, T Herman, R Gonzales 1999 The mechanism of delayed selfing in Collinsia verna (Scrophulariaceae). Am J Bot 86:1239-1247.

Kalisz S, DW Vogler, KM Hanley 2004 Context-dependent autonomous self-fertilization yields reproductive assurance and mixed mating. Nature 430:884-887.

Kliber A, CG Eckert 2004 Sequential decline in allocation among flowers within inflorescences: proximate mechanisms and adaptive significance. Ecology 85:1675-1687.

Klips R, AA Snow 1997 Delayed autonomous self-pollination in Hibiscus laevis (Malvaceae). Am J Bot 84:48-53.

Knight TM, JA Steets, JC Vamosi, SJ Mazer, M Burd, DR Campbell, MR Dudash, MO Johnston, RJ Mitchell, T-L Ashman 2005 Pollen limitation of plant reproduction: pattern and process. Annu Rev Ecol Evol Syst 36:467-497.
Kron P, SC Stewart, A Back 1993 Self-compatibility, autonomous self-pollination, and insect-mediated pollination in the clonal species Iris versicolor. Can J Bot 71:1503-1509.

Larson BMH, SCH Barrett 2000 A comparative analysis of pollen limitation in flowering plants. Biol J Linn Soc 69:503-520.

Lasso E, JD Ackerman 2004 The flexible breeding system of Weraubia sintenisii, a cloud forest bromeliad from Puerto Rico. Biotropica 36:414-417.

Levri MA 2000 A measure of the various modes of inbreeding in Kalmia latifolia. Ann Bot 86:415-420.

Lloyd DG 1979 Some reproductive factors affecting the selection of self-fertilization in plants. Am Nat 113:67-79.

1992 Self- and cross-fertilization in plants. II. The selection of self-fertilization. Int J Plant Sci 153:370-380.

Lloyd DG, DJ Schoen 1992 Self- and cross-fertilization in plants. I. Functional dimensions. Int J Plant Sci 153:358-369.

Macnair MR, QJ Cumbes 1990 The pattern of sexual resourceallocation in the yellow monkey flower, Mimulus guttatus. Proc R Soc B Biol Sci 242:101-107.

Mallick SA 2001 Facultative dichogamy and reproductive assurance in partially protandrous plants. Oikos 95:533-536.

Morgan MT, WG Wilson 2005 Self-fertilization and the escape from pollen limitation in variable pollination environments. Evolution 59:1143-1148

Motten AF 1982 Autogamy and competition for pollinators in Hepatica americana (Ranunculaceae). Am J Bot 69:1296-1305.

1986 Pollination ecology of the spring wildflower community of a temperate deciduous forest. Ecol Monogr 56:21-42.

Mulvaney CR, B Molano-Flores, DW Whitman 2004 The reproductive biology of Agalinis auriculata (Michx.) Raf. (Orobanchaceae), a threatened North American prairie inhabitant. Int J Plant Sci 165: 605-614.

Nagy ES, L Strong, LF Galloway 1999 Contribution of delayed autonomous selfing to reproductive success in mountain laurel, Kalmia latifolia (Ericaceae). Am Midl Nat 142:39-46.

Navarro L 1997 Is the dichogamy of Salvia verbenaca (Lamiaceae) an effective barrier to self-fertilization? Plant Syst Evol 207: 111-117.

Neel MC 2002 Conservation implications of the reproductive ecology of Agalinis acuta (Scrophulariaceae). Am J Bot 89: 972-980.

Ortega-Olivencia A, JP Carrasco, JA Devesa-Alcaraz 1995 Floral and reproductive biology of Drosophyllum lusitanicum (L.) Link (Droseraceae). Bot J Linn Soc 118:331-351.

Ortega-Olivencia A, JAL Paredes, T Rodriguez-Riano, JA Devesa 1998 Modes of self-pollination and absence of cryptic selfincompatibility in Drosophyllum lusitanicum (Droseraceae). Bot Acta 111:474-480.

Osborn MM, PG Kevan, MA Lane 1986 Pollination biology of Opuntia polycantha and Opuntia phaecantha (Cactaceae). Plant Syst Evol 159:85-94.

Pailler T, B Warren, JN Labat 2002 Reproductive biology of Aloe mayottensis (Liliaceae), a species endemic to the island of Mayotte (Indian Ocean). Can J Bot 80:340-348.

Paulus HF, C Gack 1990 Pollinators as prepollinating isolating factors: evolution and speciation in Ophrys (Orchidaceae). Isr J Bot 39:43-79.

Petanidou T, AC Ellis-Adam, JCM den Nijs, JGB Oostermeijer 1998 Pollination ecology of Gentianella uliginosa, a rare annual of the Dutch coastal dunes. Nord J Bot 18:537-548.

Pouvreau A, R Coutin, C Descoins 1988 La pollinisation des Ophrys (Orchidaceae) et le pseudo-accouplement des Hyménoptères males. Boll Zool Agrar Bachic Ser II 20:37-60.

Primack RB, DW Inouye 1993 Factors affecting pollinator visitation rates: a biogeographic comparison. Curr Sci 65:257-262. 
Ramírez N, A Seres 1994 Plant reproductive biology of herbaceous monocots in a Venezuelan tropical cloud forest. Plant Syst Evol 190: 129-142.

Ramsey M, L Seed, G Vaughton 2003 Delayed selfing and low levels of inbreeding depression in Hibiscus trionum (Malvaceae). Aust J Bot 51:275-281.

Rathcke BJ, LA Real 1993 Autogamy and inbreeding depression in mountain laurel, Kalmia latifolia (Ericaceae). Am J Bot 80:143-146.

Robertson C 1928 Flowers and insects: lists of visitors of four hundred and fifty-three flowers. Science Press, Lancaster, PA. 221 pp.

Ruan CJ, P Qin, ZX He 2004 Delayed autonomous selfing in Kosteletzkya virginica (Malvaceae). S Afr J Bot 70:640-645.

Sahley CT 1996 Bat and hummingbird pollination of an autotetraploid columnar cactus, Weberbanerocereus weberbaneri (Cactaceae). Am J Bot 83:1329-1336.

Sargent RD, SP Otto 2004 A phylogenetic analysis of pollination mode and the evolution of dichogamy in angiosperms. Evol Ecol Res 6:1183-1199.

Sato H 2002 The role of autonomous self-pollination in floral longevity in varieties of Impatiens hypophylla (Balsaminaceae). Am J Bot 89:263-269.

Schelssman MA 1985 Floral biology of American ginseng (Panax quiquefolium). Bull Torrey Bot Club 112:129-133.

Schemske DW, MF Willson, MN Melampy, LJ Miller, L Verner, K Schemske, LB Best 1978 Flowering ecology of some spring woodland herbs. Ecology 59:351-366.

Schiestl FP, M Ayasse, HF Paulus, C Löfstedt, BS Hansson, F Ibarra, W Francke 1999 Orchid pollination by sexual swindle. Nature 399:421-422.

Schiestl FP, R Peakall, J Mant, F Ibarra, C Schultz, S Francke, W Francke 2003 The chemistry of sexual deception. Science 302:437-438.

Schoen DJ, AHD Brown 1991 Whole and part-flower self-pollination in Clycine clandestina and G. argyea and the evolution of autogamy. Evolution 45:1651-1654.

Schoen DJ, DG Lloyd 1992 Self- and cross-fertilization in plants. III. Methods for studying modes and functional aspects of selffertilization. Int J Plant Sci 153:381-393.

Schueller SK 2004 Self-pollination in island and mainland populations of the introduced hummingbird-pollinated plant, Nicotiana glauca (Solanaceae). Am J Bot 91:672-681.

Seres A, N Ramírez 1995 Biología floral y polinización de algunas monocotiledóneas de un bosque nublado Venezolano. Ann Mo Bot Gard 82:61-81.

Simpson BB, JL Neff, G Dieringer 1986 Reproductive biology of Tinantia anomala (Commelinaceae). Bull Torrey Bot Club 113: 149-158.
Smith BH, ML Ronsheim, KR Swartz 1986 Reproductive ecology of Jeffersonia diphylla (Berberidaceae). Am J Bot 73:14161426 .

Stebbins GL 1974 Flowering plants: evolution beyond the species level. Belknap, Cambridge, MA. 397 pp.

Sun SG, YH Guo, RW Gituru, SQ Huang 2005 Corolla wilting facilitates delayed autonomous self-pollination in Pedicularis dunniana (Orobanchaceae). Plant Syst Evol 251:229-237.

Totland Ø, B Schulte-Herbruggen 2003 Breeding system, insect flower visitation, and floral traits of two alpine Cerastium species in Norway. Arct Antarct Alp Res 35:242-247.

van der Cingel NA 1995 An atlas of orchid pollination: European orchids. Balkema, Rotterdam.

Vasek FC 1964 Outcrossing in natural populations. I. The Breckinridge Mountain population of Clarkia exilis. Evolution 18: 213-218.

Vogel S 1954 Blütenbiologische Typen als Elemente der Sippengliederung. Bot Stud 1:1-338.

Vos WT, TJ Edwards, J Vanstaden 1994 Pollination biology of annual and perennial Leonotis species (Lamiaceae). Plant Syst Evol 192:1-9.

Wagner WL, SG Weller, AK Sakai 2005 Monograph of Schiedea (Caryophyllaceae subfam. Alsinoideae). Syst Bot Monogr 72: $1-169$.

Wang YQ, DX Zhang, SS Renner, ZY Chen 2004 A new selfpollination mechanism. Nature 431:39-40.

Waser NM, L Chittka, MV Price, NM Williams, J Ollerton 1996 Generalization in pollination systems, and why it matters. Ecology 77:1043-1060.

Wendt T, MBF Canela, DE Klein, RI Rios 2002 Selfing facilitates reproductive isolation among three sympatric species of Pitcairnia (Bromeliaceae). Plant Syst Evol 232:201-212.

Wesselingh RA, M Witteveldt, J Morissette, HCM den Nijs 1999 Reproductive ecology of understory species in a tropical montane forest in Costa Rica. Biotropica 31:637-645.

Wilson P, MC Castellanos, A Wolfe, JD Thomson 2005 Shifts between bee- and bird-pollination among penstemons. Pages 47-68 in N Waser, J Ollerton, eds. Specialization and generalization in plant-pollinator interactions. University of Chicago Press, Chicago.

Zhang L, SCH Barrett, J-Y Gao, J Chen, WW Cole, Y Liu, ZL Bai, Q-J Li 2005 Predicting mating patterns from pollination syndromes: the case of "sapromyiophily" in Tacca chantrieri (Taccaceae). Am J Bot 92:517-524.

Zink RA, NT Wheelwright 1997 Facultative self-pollination in island irises. Am Midl Nat 137:72-78. 